\title{
Systemic and local antibiotic prophylaxis in the prevention of
} Staphylococcus epidermidis graft infection Huseyin Turgut ${ }^{\dagger 1}$, Suzan Sacar*†1, Ilknur Kaleli², Mustafa Sacar ${ }^{\dagger 3}$, Ibrahim Goksin ${ }^{3}$, Semra Toprak ${ }^{1}$, Ali Asan ${ }^{1}$, Nural Cevahir ${ }^{2}$, Koray Tekin ${ }^{4}$ and Ahmet Baltalarli ${ }^{3}$

\begin{abstract}
Address: ${ }^{1}$ Department of Infectious Diseases and Clinical Microbiology, Pamukkale University, Faculty of Medicine, Denizli, Turkey, ${ }^{2}$ Departmen of Microbiology and Clinical Microbiology, Pamukkale University, Faculty of Medicine, Denizli, Turkey, ${ }^{3}$ Department of Cardiovascular Surgery, Pamukkale University, Faculty of Medicine, Denizli, Turkey and ${ }^{4}$ Department of General Surgery, Pamukkale University, Faculty of Medicine, Denizli, Turkey

Email: Huseyin Turgut - hturgut@pamukkale.edu.tr; Suzan Sacar* - suzansacar@yahoo.com; Ilknur Kaleli - bkaleli@hotmail.com; Mustafa Sacar - mustafasacar@hotmail.com; Ibrahim Goksin - ibrahimgoksin@yahoo.com; Semra Toprak - drsemratoprak@hotmail.com; Ali Asan - draasan@yahoo.com; Nural Cevahir - cevahir@pamukkale.edu.tr; Koray Tekin - koraytekin@yahoo.com;

Ahmet Baltalarli - baltalar@pamukkale.edu.tr

* Corresponding author †Equal contributors
\end{abstract}

Published: 21 October 2005

BMC Infectious Diseases 2005, 5:91 doi:10.1186/1471-2334-5-91
Received: II June 2005

Accepted: 21 October 2005

This article is available from: http://www.biomedcentral.com/|47|-2334/5/9 |

(C) 2005 Turgut et al; licensee BioMed Central Ltd.

This is an Open Access article distributed under the terms of the Creative Commons Attribution License (http://creativecommons.org/licenses/by/2.0), which permits unrestricted use, distribution, and reproduction in any medium, provided the original work is properly cited.

\begin{abstract}
Background: The aim of the study was to investigate the in vivo efficacy of local and systemic antibiotic prophylaxis in the prevention of Staphylococcus (S.) epidermidis graft infection in a rat model and to evaluate the bacterial adherence to frequently used prosthetic graft materials.

Methods: Graft infections were established in the subcutaneous tissue of 120 male Wistar rats by implantation of Dacron/ePTFE grafts followed by topical inoculation with $2 \times 10^{7}$ CFUs of clinical isolate of methicillin-resistant $S$. epidermidis. Each of the graft series included a control group, one contaminated group that did not receive any antibiotic prophylaxis, two contaminated groups that received systemic prophylaxis with teicoplanin or levofloxacin and two contaminated groups that received teicoplanin-soaked or levofloxacin-soaked grafts. The grafts were removed 7 days after implantation and evaluated by quantitative culture.

Results: There was significant bacterial growth inhibition in the groups given systemic or local prophylaxis $(P<0.05)$. Methicillin-resistant $S$. epidermidis had greater affinity to Dacron graft when compared with ePTFE graft in the untreated contaminated groups $(P<0.05)$.

Conclusion: The study demonstrated that the usage of systemic or local prophylaxis and preference of ePTFE graft can be useful in reducing the risk of vascular graft infections caused by staphylococcal strains with high levels of resistance.
\end{abstract}

\section{Background}

One of the most feared complications of the use of a pros-

thetic material is the appearance of infection after implant
[1-5]. Graft infection often results in prolonged hospitalization, organ failure, amputation and death $[4,6,7]$. The causative organisms are predominantly $S$. auerus and S. 
epidermidis $[4,8]$. Most commonly contamination occurs at the time of graft insertion and the most frequent source of infection is from staphylococci from the patient's skin $[3,4,9]$. The most important strategies for the prevention of prosthetic infection are asepsis and the perioperative administration of systemic antibiotics [10-12]. Moreover, in the case of vascular grafts, alternative methods such as antimicrobials bound in high concentrations to prosthetic grafts have been proposed $[2,10,11,13]$.

However, the antibiotic usage should be guided by local bacterial prevalence and sensitivities, remembering that most infections are caused by staphylococci. Levofloxacin is a fluoroquinolone with an enhanced activity against gram-positive cocci $[14,15]$. Teicoplanin is a glycopeptide antibiotic and has an excellent bactericidal activity against penicillinase-producing and methicillin-resistant S. epidermidis $[16,17]$.

Synthetic vascular prostheses have been developed to supplement the limited supply of native graft materials. But they may act as a foreign body in the patient and may harbour bacteria which results in graft infection [18]. Vascular graft composition and construction have been shown to influence bacterial adherence $[3,19]$.

The aim of the present study was to investigate the in vivo efficacy of local and systemic antibiotic prophylaxis in the prevention of $S$. epidermidis graft infection in a rat model and to evaluate the bacterial adherence to frequently used prosthetic graft materials.

\section{Methods}

This study was carried out in the animal laboratory of our institution. All animals received humane care in compliance with Principles of Laboratory Animal Care, formulated by the Guide for the Care and Use of Laboratory Animals, prepared by the National Academy of Sciences [20]. This study was also approved by the Pamukkale University Animal Research Ethics Committee, Denizli, Turkey.

The strain of methicillin-resistant $S$. epidermidis used in the present study was isolated from a clinical specimen (graft infection) submitted for routine bacteriological investigation. Identification of the clinical isolate was determined by Gram staining, catalase reaction, tube coagulation test and Api-staph test (biomérieux, Lyon, France). Methicillin sensitivity was investigated by oxacillin disk diffusion test [21]. Levofloxacin and teicoplanin (both from Aventis Pharma) were diluted in accordance with manifacturers' recommendations yielding $1 \mathrm{mg} / \mathrm{ml}$ stock solution. Solutions of drugs were made fresh on the day of assay.
One-hundred and twenty adult male Wistar rats (weight range 300 to $350 \mathrm{~g}$ ) were used in this study. The study included two series composed of 6 groups for each of the woven, gelatin-imregnated polyethyleneterephthalate (Dacron) (Gelwave, Sulzer Vascutek) (D1-6) and expanded polytetrafluoroethylene (ePTFE) (Alpha Graft ${ }^{\oplus}$, Alpha Research) (P1-6) grafts. Each of the series included one group with no graft contamination and no antibiotic prophylaxis (uncontaminated control, Dacron1, ePTFE1), one contaminated group that did not receive any antibiotic prophylaxis (untreated control, Dacron2, ePTFE2), one contaminated group that recieved teicoplanin-soaked grafts (Dacron3, ePTFE3), one contaminated group in which perioperative intraperitoneal prophylaxis with teicoplanin $(10 \mathrm{mg} / \mathrm{kg})$ was administered (Dacron4, ePTFE4), one contaminated group that recieved levofloxacin-soked grafts (Dacron5, ePTFE5) and one contaminated group in wich perioperative intraperitoneal prophylaxis with levofloxacin $(10 \mathrm{mg} / \mathrm{kg}$ ) (Dacron6, ePTFE6) was administered. Each rat was anesthetized with a 2:1 mixture of kethamine hydrochloride $(100 \mathrm{mg} / \mathrm{ml})$ (Pfizer):xylazine hydrochloride $(20 \mathrm{mg} / \mathrm{ml})$ (Bayer) at a dose of $0.75 \mathrm{ml} / \mathrm{kg}$ intramuscularly. Rats' hair of the back was shaved and the skin was cleaned with $10 \%$ povidoneiodine solution. One subcutaneous pocket was made on each side of the median line by a $1.5 \mathrm{~cm}$ incision. Aseptically, $1-\mathrm{cm}^{2}$ sterile collagen-sealed Dacron or ePTFE grafts were implanted into the pockets. Prior to implantation, in the groups Dacron3, ePTFE3 and Dacron5, ePTFE5 the Dacron and ePTFE graft segments were impregnated with $1 \mathrm{mg} / \mathrm{ml}$ teicoplanin and levofloxacin, respectively. Antibiotic bonding was obtained immediately before implantation by soaking grafts for 20 minutes in a sterile solution of antibiotic. The effect of preoperative intraperitoneal teicoplanin and levofloxacin administered 30 minutes before implantation at the standard dose of $10 \mathrm{mg} / \mathrm{kg}$ was evalueted in the groups Dacron4, ePTFE4 and Dacron6, ePTFE6, respectively. The pockets were closed by means of skin clips and sterile saline solution $(1 \mathrm{ml})$ containing methicillin-resistant strain S.epidermidis at a concentration of $2 \times 10^{7} \mathrm{CFUs} / \mathrm{ml}$ was inoculated onto the graft surface by using a tuberculin syringe to create a subcutaneous fluid-filled pocket. The animals were returned to individual cages and thoroughly examined daily. All grafts were removed 7 days following implantation.

The explanted grafts were placed in sterile tubes, washed in sterile saline solution, placed in tubes containing $10 \mathrm{ml}$ of phosphate-buffered saline solution and sonicated for 5 minutes to remove the adherent bacteria from the grafts. Quantitation of viable bacteria was performed by culturing serial dilutions $(0.1 \mathrm{ml})$ of the bacterial suspension on blood agar plates. All plates were incubated at $37^{\circ} \mathrm{C}$ for 48 hours and evaluated for the presence of the staphylococcal 
Table I: Quantitative microbiological results of the in vivo experiments.

\begin{tabular}{|c|c|c|c|}
\hline Group ${ }^{a}$ & Graft-bonded drugb & Intraperitoneal preoperative drugc & $\begin{array}{l}\text { Quantitative graft culture (CFUs/ } \\
\mathrm{ml})\end{array}$ \\
\hline Dacron Id,e & -- & -- & 0.0 \\
\hline Dacron 2 & -- & -- & $3.7 \times 10^{7} \pm 1.1 \times 10^{7}$ \\
\hline Dacron $3^{\mathrm{d}, \mathrm{e}}$ & Teicoplanin & -- & $5.6 \times 10^{3} \pm 1.2 \times 10^{3}$ \\
\hline Dacron 4d,e & -- & Teicoplanin & $5.3 \times 10^{2} \pm 1.2 \times 10^{2}$ \\
\hline Dacron $5^{d}$ & Levofloxacin & -- & $4.0 \times 10^{5} \pm 5.5 \times 10^{4}$ \\
\hline Dacron $6^{\mathrm{d}, \mathrm{e}}$ & -- & Levofloxacin & $4.9 \times 10^{4} \pm 4.7 \times 10^{3}$ \\
\hline ePTFE Id,e & -- & -- & 0.0 \\
\hline ePTFE $2^{d}$ & -- & -- & $5.3 \times 10^{6} \pm 2.4 \times 10^{6}$ \\
\hline ePTFE $3^{\mathrm{d}, \mathrm{e}}$ & Teicoplanin & -- & $4.7 \times 10^{3} \pm 1.2 \times 10^{3}$ \\
\hline ePTFE 4d,e & -- & Teicoplanin & $4.2 \times 10^{2} \pm 1.4 \times 10^{2}$ \\
\hline ePTFE $5^{d}$ & Levofloxacin & -- & $3.7 \times 10^{5} \pm 2.8 \times 10^{4}$ \\
\hline ePTFE 6d,e & -- & Levofloxacin & $4.7 \times 10^{4} \pm 4.1 \times 10^{3}$ \\
\hline
\end{tabular}

a Each group was performed by 10 animals; Dacron I-6, groups of animals by implantation of Dacron protheses; ePTFEI-6, groups of animals by implantation of ePTFE protheses.

b Graft segments were impregnated with I mg/ml teicoplanin; I mg/ml levofloxacin.

c Teicoplanin $10 \mathrm{mg} / \mathrm{kg}$, levofloxacin $10 \mathrm{mg} / \mathrm{kg}$.

d Statistically significant when compared with group Dacron2

e Statistically significant when compared with group ePTFE2

strains. The organisms were quantitated by counting the number of colony-forming units (CFUs) per plate.

Quantitative culture results were presented as arithmetic mean \pm standard deviation (S.D.). Differences among the groups were evaluated using one-way analysis of variance (ANOVA), and multiple comparisons between the groups were performed with a posthoc test (Tukey's HSD test). Differences were considered statistically significant when $P<0.05$. Data were analyzed by a statistical software (SPSS for Windows 11.0; SPSS, Chicago, Illinois).

\section{Results}

None of the animals included in any group died or had clinical evidence of drug related adverse effects, such as local signs of perigraft inflammation, anorexia, vomiting, diarrhoea, and behavioural alterations.

There was no anatomic and microbiological evidence of graft infection in the animals included in the uncontaminated control groups. In contrast, all 20 rats included in the untreated contaminated control groups (Dacron2 and ePTFE2) demonstrated evidence of graft infection, with quantitative culture results showing $3.7 \times 10^{7} \pm 1.1 \times 10^{7}$ $\mathrm{CFU} / \mathrm{ml}$ and $5.3 \times 10^{6} \pm 2.4 \times 10^{6} \mathrm{CFU} / \mathrm{ml}$, respectively. The quantitative graft cultures of the other groups demonstrated bacterial growth in different counts. The results are summarised in Table 1.

The amount of bacterial growth was statistically significantly higher in untreated contaminated Dacron-group (Dacron2) when compared to the other groups $(P<0.05)$.
The second highest bacterial growth was observed in untreated contaminated ePTFE-group (ePTFE2) and it was also significantly different from all antibiotic-treated groups, except levofloxacin-bonded Dacron (Dacron5) and ePTFE (ePTFE5) groups $(P<0.05)$. Although the highest reduction in bacterial growth number was observed in the intraperitoneal teicoplanin groups (Dacron4 and ePTFE4), there was no statistically significant difference among the treated contaminated groups $(P$ $>0.05)$.

\section{Discussion}

Various studies have demonstrated that systemic antibiotic prophylaxis reduces the incidence of prosthetic vascular graft infections, but not completely prevent them [2224]. That's because antibiotic impregnated grafts are arousing interest as they can deliver antibiotic at the time that the graft is at the greatest risk of contamination [22].

In vascular surgery, S. epidermidis has been shown to be the leading isolate with infection appearing late after implantation $[3,25,26]$. So, in order to simulate the clinical setting, we preferred to use an isolate of $S$. epidermidis which was obtained from an infected vascular conduit in our hospital.

Teicoplanin and levofloxacin are attractive options for local and systemic antibiotic prophylaxis in preventing $S$. epidermidis graft infections, because they are effective antibiotics against coagulase positive and negative staphylococci $[23,27]$. Teicoplanin is used parenterally to treat infections caused by staphylococcal infections since the 
emergence of methicillin-resistant staphylococci [28]. Recently, teicoplanin has been administered as perioperative antibiotic prophylaxis [29-31]. Teicoplanin has a long half-life and good tissue and bone penetration [32]. In an earlier study at St James's University Hospital, teicoplanin exhibited good penetration into ischaemic tissue, which may be desirable for prophylaxis in vascular surgery [33]. Kester et al. [34] concluded from a two-centre study that a single dose of teicoplanin showed similar efficacy to a three-dose regimen of cephradine plus metronidazole as prophylaxis for wound infection in vascular surgery. It was showed that levofloxacin had greater in vitro and in vivo anti-staphylococcal activity than the other fluoroquinolones such as ofloxacin or ciprofloxacin [35-37]. In previous studies levofloxacin was reported to reach high concentrations in serum and various tissues, following single dose levofloxacin administration [38,39]. In the present study it was found that both local and systemic levofloxacin usage reduced bacterial count in the graft segments when compared to untreated contaminated controls (Dacron2 and ePTFE2). Although it was not statistically significant, systemic usage of levofloxacin was more effective than the local one. However, interestingly, the reducing efficacy of local usage of levofloxacin on bacterial count was also inadequate to reach a statistical difference when compared to untreated contaminated ePTFE graft (ePTFE2) $(P>0.05)$.

The question remains whether local or systemic antibiotic prophylaxis is the best choice for reducing the risk of prosthetic vascular graft infection. When a local prophylaxis is used, the dose of antibiotic delivered to the operative site could be important in eliminating infections, as most of them are due to contamination at the time of implantation. Simple soaking in an antibiotic solution immediately prior to implantation is an easy way of impregnating the prosthetic graft that can be done extemporaneously by the surgeon himself. But during this procedure the risk of contamination of the graft increases.

Antibiotics having good activity against gram-positive bacteria were used in bonding vascular grafts in experimental models. Hernandez-Richter et al. [40] found that rifampicin and triclosan but not silver was effective in preventing bacterial infection of vascular Dacron graft material. Giacometti et al. [41] confirmed the efficacy of mupirocin-soaked grafts against methicillin-susceptible, methicillin-resistant and vancomycin-intermediate $S$. epidemidis. Ghiselli et al. [42] showed that Temporin A had an antibacterial in vitro activity against methicillin-susceptible and methicillin-resistant $S$. epidermidis. Efficacy of polycationic peptides in preventing vascular graft infection due to methicillin-resistant $S$. aureus with intermediate resistance to glycopeptides was demonstrated to be very good [11]. Dell'Acqua et al. [43] suggested that
RNAIII-inhibiting peptide (YSPWTNF-NH2), applied locally and systemically, can completely inhibit drugresistant $S$. aureus and $S$. epidermidis biofilms. Osada et al. [44] demostrated that levofloxacin incorporated into albumin-sealed Dacron graft had a bactericidal action and adhesive prevention against inoculated $S$. aureus in a graft model.

Soaking of the grafts in solutions of $1 \mathrm{mg} / \mathrm{ml}$ of different antibiotics has been shown to be effective in making antibiotic-bonding drugs [45]. Previously, Levofloxacin and teicoplanin, used in $10 \mathrm{mg} / \mathrm{kg}$ consantration have been shown to be successful in reducing the risk of prosthetic graft infection [23]. We chosed the same concentrations for the each antibiotic in our model according to these studies' findings.

Our data indicate that, although the difference was not statistically significant, local usage of teicoplanin more effectively reduces the bacterial count in graft segments than the local levofloxacin application and it seems to be the most appropriate antibiotic for local vascular graft prophylaxis. The finding that antibiotic-impregnated grafts alone can not prevent prosthetic vascular graft infection is similar to the results found by other groups $[11,22]$. The combined usage of systemic antibiotic prophylaxis and drug-bonded grafts has been shown to be more effective in decreasing the incidence of prosthetic vascular graft infections $[10,23]$. But this combination may have disadvantages like increased intraoperatif contamination risk and cost.

The results of this study demonstrated that both systemic and local prophylactic antibiotic treatment was useful. Although, the difference was not significant, the highest reduction in bacterial number was in the intraperitoneal teicoplanin groups in our study and this finding is parallel with previous studies, [23,37]. Second reason for choosing teicoplanin was its advantage as single dose application. This is certainly more desirable than frequent dosing required by conventional systemic antibiotics or other glycopeptides.

All kinds of prosthetic vascular grafts are susceptible in varying degrees to infection via direct contamination during implantation or bacteremia after operation. Dacron and ePTFE are the most frequently used materials. Surface area and molecular structure differs between the two types of grafts. Graft material of ePTFE is relatively nonporous when it is compared with multifilamented Dacron grafts. EPTFE is more hydrophobic than Dacron, perhaps that's why it is less likely to form bonds with those bacteria in which the cell walls have hydrophobic properties $[19,46]$. The findings of the present study was similar with previous studies reporting that $S$. epidermidis, S. aureus and 
Escherichia coli had greater affinity to Dacron graft when compared with ePTFE $[19,47,48]$. The bacterial count in the untreated contaminated ePTFE grafts was very low than the untreated contaminated Dacron groups. Untreated contaminated ePTFE graft was found to be almost as effective as levofloxacin-bonded Dacron and ePTFE grafts. Although there were not statistical signifficant differences among the treated contaminated groups, it was observed that bacterial growth was more in Dacron grafts. This finding may be of a clinical importance and may influence the choice of a surgeon when he has to prefer one of these grafts.

Further animal studies are needed to assess the efficacy of commercially available grafts soaked in various antibiotic solutions, against infections after sequental bacterial seeding for up 7 days. Additionally, these results have to be compared with the real situation of an implanted graft in a living human being. It should not be forgotten that antibiotic/antiseptic impregnation is not the only way of protecting synthetic grafts. Modifying the surface characteristics of prosthetic graft to minimise bacterial adherence needs to be investigated further.

\section{Conclusion}

The study demonstrated that the usage of systemic or local prophylaxis and preference of ePTFE graft can be useful in reducing the risk of vascular graft infections caused by staphylococcal strains with high levels of resistance.

\section{Competing interests}

The author(s) declare that they have no competing interests.

\section{Authors' contributions}

HT and SS jointly conceived of the study, secured funding, participated in its design and coordination and co-drafted the manuscript. MS and $\mathrm{AB}$ participated in the design and coordination of the study, data analysis and writing the paper. IK, NC and ST participated in the microbiological studies and data analysis. IG and AA participated in the administration of the drugs and in the conduct of the animals' experiments. KT performed the statistical analysis and revised the manuscript. All authors read and approved the final manuscript.

\section{References}

I. Soetevent C, Klemm PL, Stalenhoef AF, Bredie SJ: Vascular graft infection in aortoiliac and aortofemoral bypass surgery: clinical presentation, diagnostic strategies and results of surgical treatment. Neth J Med 2004, 62(I I):446-52.

2. Bunt TJ: Vascular graft infections: an update. J Cardiovasc Surg 2001, 9(3):225-233.

3. Jones L, Braithwaite BD, Davies B, Heather BP, Earnshaw J]: Mechanism of late prosthetic vascular graft infection. J Cardiovasc Surg 1997, 5(5):486-489.
4. Bergamini TM, Corpus RA, Brittian KR, Peyton JC, Cheadle WG: The natural history of bacterial biofilm graft infection. J Surg Res 1994, 56:393-396.

5. Taylor G, Gravel D, Johnston L, Embil J, Holton D, Paton S: Prospective surveillance for primary bloodstream infections occurring in Canadian hemodialysis units. Infect Control Hosp Epidemiol 2002, 23(1 2):716-20.

6. Mingoli A, Sapienza P, Di Marzo L, Sgarzini G, Burchi C, Modini C, Cavallaro A: Management of abdominal aortic prosthetic graft infection requiring emergent treatment. Angiology 1997, 48(6):49|-495.

7. Seeger JM, Pretus HA, Welborn MB, Ozaki CK, Flynn TC, Huber TS: Long-term outcome after treatment of aortic graft infection with staged extra-anatomic bypass grafting and aortic graft removal. J Vasc Surg 2000, 32(3):45I-46I.

8. Abdulrahman IS, AI-Mueilo SH, Bokhary HA, Ladipo GOA, Al-Rubaish $A$ : A prospective study of hemodialysis access-related bacterial infections. J Infect Chemother 2002, 8:242-246.

9. Liekwig WG, Greenfield LJ: Vascular graft infection: collected experience and results of treatment. Surgery 1977, 81:335-342.

10. Ghiselli R, Giacometti A, Cirioni O, Mocchegiani F, Orlando F, Del Prete MS, D'Amato G, Scalise G, Saba V: Quinopristin/dalfopristin bonding in combination with intraperitoneal antibiotics prevent infection of knitted plyester graft material in a subcutaneous rat pouch model infected with resistant Staphylococcus epidermidis . Eur J Vasc Endovasc Surg 2002, 24:230-234

II. Giacometti A, Cirioni O, Ghiselli R, Goffi L, Moccheigiani F, Riva A, Scalise G, Saba V: Efficacy of polycationic peptides in preventing vascular graft infection due to Staphylococcus epidermidis. I Antimicrob Chemother 2000, 46:75I-756.

12. Hasselgren PO, Ivarsson L, Risberg B, Sheeman T: Effects of prophylactic antibiotics in vascular surgery. A prospective randomised double blind study. Ann Surg 1984, 200:86-92.

13. Hennes N, Sandmann W, Torsello G, Kniemeyer HW, Grabitz K: Infection of a vascular prosthesis-a retrospective analysis of 99 cases. Chirurg 1996, 67(1):37-43.

14. Casellas JM, Gilardoni M, Tomè G, Goldberg M, Ivanovich S, Orduna M, Dolmann A, Ascoli M, Ariza H, Montero JM: Comparative invitro activity of levofloxacin against isolates of bacteria from adult patients with community-acquired lower respiratory tract infections. Antimicrob Chemother 1999, 43(3):37-42.

15. Soussy CJ, Cluzel M, Ploy MC, Kitzis MD, Morel C, Bryskier A, Courvalin $P$ : In-vitro antibacterial activity of levofloxacin against hospital isolates: a multicentre study. I Antimicrob Chemother 1999, 43(3):43-50

16. Pauluzzi S, Del Favero A, Menichetti F, Barrata E, Moretti VM, Di Fillipo F, Pasticci MB, Guerciolini R, Patoia L, Frongillo RF: Treatment of infections by staphylococci and other gram-positive bacteria with teicoplanin: an open study. J Antimicrob Chemother 1987, 20:43I-438.

17. De Lalla F, Santoro D, Rinaldi E, Suter F, Cruciani M, Guaglianone MH, Rizzardini G, Pellegata G: Teicoplanin in the treatment of infections by staphylococci, Clostridium difficil and other grampositive bacteria. J Antimicrob Chemother 1989, 23: I3I-142.

18. Thomas A, Campbell GR, Campbell JH: Advances in vascular tissue engineering. Cardiovasc Pathol 2003, I 2:27I-276.

19. Schmitt DD, Bandyk DF, Pequet AJ, Towne JB: Bacterial adherence to vascular protheses. J Vasc Surg 1986, 3(5):732-40.

20. Institute of Laboratory Animal Resources National Research Council: Guide for the care and use of laboratory animals. Washington, DC: National Academy Press; 1996.

21. Kloos WE, Barnerman TL: Staphylococcus and Micrococcus. In Manual of Clinical Microbiology 7th edition. Edited by: Murray PR, Baron EJ, Pfaller MA, Tenover FC, Yolken RH. Washington: ASM Press; 1999:264-277.

22. Lenhgharardit FJ, Torsello G, Claeys LGY, Pfeiffer M, WacholDrewek Z, Grundmann RT, Sandmann W: Systemic and local antibiotic prophylaxis in the prevention of prosthetic vascular graft infection: an experimental study. Eur J Vasc Surg 2002, 23:127-133.

23. Ghiselli R, Giacometti A, Goffi L, Cirioni O, Boccoli G, Mocchegiani F, Riva A, Scalise G, Saba V: Efficacy of rifampin-levofloxacin as a prophylactic agent in preventing Staphylococcus epidermidis graft infection. Eur J Vasc Endovasc Surg 2000, 20(6):508-5 I I. 
24. Ghiselli R, Giacometti A, Goffi L, Cirioni O, Mocchegaiani F, Orlando F, Paggi AM, Petrelli E, Scalise G, Saba V: Prophylaxis against Staphylococcus aureus vascular graft infection with mupirocinsoaked, collagen-sealed Dacron. J Surg Res 200I, 99:3 I6-320.

25. Sladen JG, Chen JC, Reid JDS: An aggresive local approach to vascular graft infection. Am / Surg 1998, I76:222-225.

26. Bandyk DF, Berni GA, Thiele BL, Towne JB: Aortofemoral graft infection due to Staphylococcus epidermidis. Arch Surg 1984, I I (I): 102-108.

27. Murase K, Hirose H, Mori $Y$, Takagi H, Iwata H, Sago T, Kawamura $Y$ : Graft-preserving treatment for vascular graft infected with Staphylococcus aureus with antibiotic-releasing porous apatite ceramic in the rabbit. J Vasc Surg 2003, 38:368-73.

28. Woodford N, Johnson AP, Mirrison D, Speller DCE: Current perspectives on glycopeptide resistance. Clin Microbiol Rev 1995, 8(4):585-6I5.

29. Lim SH, Smith MP, Salooja N, Machin SJ, Goldstone AH: A prospective randomized study of prophylactic teicoplanin to prevent early Hickman catheter related sepsis in patients receiving intensive chemotherapy for haematological malignancies. J Antimicrob Chemother 1991, 28: 109-1 I6.

30. De Lalla F, Viola R, Pellizzer G, Lazzarini L, Tramarin A, Fabris P: Regional prophylaxis with teicoplanin in monolateral or bilateral total knee replacement: an open study. Antimicrob Agents Chemother 2000, 44(2):316-319.

31. Marroni M, Cao P, Fiorio M, Maghini M, Lenti M, Repeto A, Menichetti F: Prospective, randomized, double-blind trial comparing teicoplanin and cefazolin as antibiotic prophylaxis in prosthetic vascular surgery. Eur J Clin Microbiol Infect Dis 1999, 18(3): $175-178$.

32. Suter F, Avai A, Bottura P, Fusco U, Gerundini M, Caprioli S, Maggiolo $\mathrm{F}$ : Teicoplanin versus cefamandole in the prevention of infection in total hip replacement. Eur J Clin Microbiol Infect Dis 1994 I 3(10):793-796.

33. Antrum RM, Bibby SR, Ramsden CH, Kester RC: Teicoplanin: part I. An evaluation of the concentrations seen in serum and the subcutaneous fat of the relatively ischaemic limb following a single intravenous bolus. Drugs Exp Clin Res 1989, I5:21-23.

34. Kester RC, Antrum R, Thornton CA, Ramsdenf CH, Harding I: A comparison of teicoplanin versus cephradine plus metronidazole in the prophylaxis of post-operative infection in vascular surgery. J Hosp Infect 1999, 41:233-243.

35. Von Eiff C, Peters G: In-vitro activity of ofloxacin, levofloxacin and D-ofloxacin against staphylococci. J Antimicrob Chemother 1996, 38:259-263.

36. Gesu GP, Marchetti F, Piccoli L, Cavallero A: Levofloxacin and ciprofloxacin in vitro activities against 4,003 clinical bacterial isolates collected in 24 Italian laboratories. Antimicrob Agents Chemother 2003, 47(2):816-819.

37. Chambers HF, Xiang Liu Q, Liuxin Chow L, Hackbarth C: Efficacy of levofloxacin for experimental aortic-valve endocarditis in rabbits infected with viridans group streptococcus or Staphylococcus aureus. Antimicrob Agents Chemother 1999, 43:2742-2746.

38. Von Baum H, Böttcher S, Hoffmann H, Sonntag HG: Tissue penetration of a single dose of levofloxacin intravenously for antibiotic prophylaxis in lung surgery. JAC 200I, I3(5):729-730.

39. Swoboda S, Oberdorfer K, Klee F, Hoppe-Tichy T, von Baum H, Geiss $\mathrm{HK}$ : Tissue and serum concentrations of levofloxacin $\mathbf{5 0 0} \mathbf{~ m g}$ administered intravenously or orally for antibiotic prophylaxis in biliary surgery. JAC 2003, $51: 459-462$.

40. Hernandez-Richter T, Schardey HM, Wittmann F, Mayr S, SchmittSody M, Blasenbreu S, Heiss MM, Gabka C, Angele MK: Rifampin and triclosan but not silver is effective in preventing bacterial infection of vascularDacron graft material. Eur J Vasc Surg 2003, 26:550-557.

41. Giacometti A, Cirioni O, Ghiselli R, Goffi L, Viticchi C, Mocchegiani F, Riva A, Orlando F, Saba V, Scalise G: Mupirocin prophylaxis against methicillin susceptible, methicillin-resistant or vancomycin-intermediate Staphylococcus epidermidis vasculargraft infection. Antimicrob Agents Chemother 2000, 44(I0):2842-2844.

42. Ghiselli $R$, Giacometti $A$, Cirioni $O$, Mocchegiani $F$, Orlando $F$ Kamysz W, Del Prete MS, Lukasiak J, Scalise G, Saba V: Temporin A as a prophylactic agent against methicillin sodium-susceptible and methicillin sodium-resistant Staphylococcus epidermidis vascular graft infection. J Vasc Surg 2002, 36:1027-30.
43. Dell'Acqua G, Giacometti A, Cirioni O, Ghiselli R, Saba V, Scalise G, Gov Y, Balaban N: Suppression of drug-resistant staphylococcal infections by the quorum-sensing inhibitor RNAllI-inhibiting peptide. J Infect Dis 2004, I 90(2):3 I8-320.

44. Osada T, Yamamura K, Fujimoto K, Mizuno K, Sakurai T, Ohta M, Nabeshima T: Prophylaxis of local vascular graft infection with levofloxacin incorporated into albumin-sealed dacron graft (LVFX-ALB Graft). Microbiol Immunol 1999, 43(4):3।7-2I.

45. Galdbart JO, Branger C, Andreassian B, Lambert-Zechovsky N, Kitzis $M$ : Elution of six antibiotics bonded to polyeyhylene vascular grafts sealed with three proteins. J Surg Res 1996, 66:174-178.

46. Falkenback D, Lundberg F, Ribbe E, Ljungh A: Exposure of plasma proteins on Dacron and ePTFE vascular material in a perfusion model. Eur J Vasc Surg 2000, 19:468-475.

47. Malangoni MA, Livingston DH, Peyton JC: Of protein Binding on the adherence of staphylococci to prosthetic vascular grafts. J Surg Res 1993, 54:168-172.

48. Camiade C, Goldschmidt P, Koskas F, Ricco JB, Jarraya M, Gerota J, Kieffer $E$ : Optimization of the resistance of arterial allografts to infection: comparative study with synthetic prostheses. Ann Vasc Surg 200I, 15:186-196.

\section{Pre-publication history}

The pre-publication history for this paper can be accessed here:

http://www.biomedcentral.com/1471-2334/5/91/prepub
Publish with Biomed Central and every scientist can read your work free of charge

"BioMed Central will be the most significant development for disseminating the results of biomedical research in our lifetime. "

Sir Paul Nurse, Cancer Research UK

Your research papers will be:

- available free of charge to the entire biomedical community

- peer reviewed and published immediately upon acceptance

- cited in PubMed and archived on PubMed Central

- yours - you keep the copyright

Submit your manuscript here:

http://www.biomedcentral.com/info/publishing_adv.asp
BioMedcentral 